\title{
Chemical Investigations of Some Commercial Samples of Calcium Based Ayurvedic Drug of Marine Origin: Kapardika Bhasma
}

\author{
Sonali Dhamal, M.P.Wadekar*, B.A.Kulkarni, V.V.Dhapte \\ Department of Chemistry, Yashwantrao Mohite College, Bharati Vidyapeeth Deemed University, \\ Pune-411038, Maharashtra, India.
}

\begin{abstract}
Kapardika bhasma is an important Ayurvedic drug of marine origin. Even though it is composed of mainly of calcium carbonate it exhibits excellent medicinal properties which are not associated with standard calcium carbonate. In the present study four commercial samples are characterized using techniques like EDX, SEM, IR, UV,XRD and TG analysis to throw light on their chemical composition and chemical properties.Such comparative study may help to standardise and to interpret the biological and medicinal properties of such traditional drug.
\end{abstract}

Keywords: Calcium carbonate, Kapardika bhasma, TG, SEM, IR, XRD.

\section{Introduction}

Ocean is the biggest natural repository providing a huge number of materials many of which are pharmaceutically important. Among these, there is a specific group of marine products of animal origin whose pharmaceutical utility and medicinal importance was recognized long ago by traditional pharmacists. This group includes five calcium based materials namely Counch [ terbinella rapa], Counch shell [xan thus pyrum], Kapardika [ cypraea moneta ], Praval [ coralliun rubrum ] and Pearl [ pinctada margarifiera].

In Indian systems of medicine a huge number of pharmaceutical preparations are established according to procedures reported in ancient ayurvedic texts. Kapardika bhasma is one of these drugs which is the subject of present investigation.

Kapardika Bhasma is a valuable Ayurvedic drug which is used as powerful antacid and many stomach problems. It is prepare from Kapardika powder. Various methods are reported in Ancient Ayurvedic literature such as Rasatarangani, Charak Sanhita. These procedures are followed by Ayurvedic pharmacy still today.

Therefore, most of these formulations are considered as traditional medicines and they are not acceptable as approved drugs on international level. Actually due to their natural and biological origin they possess several merits as compared to their equivalent drugs in current use. Economically also, they are much cheaper due to easily available raw material in huge quantity at a lower cost. Hence if their pharmaceutical and biomedical chemistry is reinvestigated by standardizing synthetic procedures and methods of characterization on the basis of modern analytical techniques, all these formulations will receive international appreciation and acceptance on wider scale.

Literature survey reveals that studies on chemical investigations of some Ayurvedic bhasmas of mineral origin are reported ${ }^{[1-4]}$ but relatively less work is reported on bhasmas of marine origin. A review on Kapardika bhasma is reported by Krishna etal ${ }^{[5]}$. Some structural characterization on Varatika bhasma (i.e. Kapardika bhasma) is also reported by Devanathan etal ${ }^{[6]}$. Some calcium based Ayurvedic bhasmas are analysed by instrumental neutron activation analysis for major and minor constituent elements by Kumar etal ${ }^{[7]}$. An attempt has been made by them to correlate metallic contents with their medicinal importance. Antacid activity of some Ayurvedic calcium preparations is studied by Baxi ${ }^{[8]}$.

In the present study Chemical investigations of some commercial samples of Kapardika bhasma are done using modern techniques such as EDX, SEM, Solid state UV, Solid state IR, TGA and XRD. Such study may throw light on chemical composition as well as structural properties of Kapardika bhasma and hence the origin of its medicinal properties. Four samples from reputed pharmacies (K-1, K-2, K-3 and K-4) from different parts of India are selected for current study in order to understand the current status of these bhasmas.

\section{Materials and Methods}

Kapardika bhasma ( K1, K2, K3, K4) from four reputed pharmacies are collected for the present study. Standard $\mathrm{CaCO}_{3}$ was purchased from Alderich for comparative purpose. Powder of Kapardika (K) was also purchased from Ayurvedic pharmacy. 


\section{Instrumental Techniques}

Calcium carbonate, Kapardika powder and samples of Kapardika bhasma were analysed using EDX machine (JEOL JSM - 6360A Analytical SEM) for obtaining the relative percentage of constituent elements. The solid state infrared spectra were recorded in $\mathrm{KBr}$ (discs) in the region $4000-450 \mathrm{~cm}-1$ on Perkin Elmer model 1600 and solid state UV-Visible spectra were recorded in the region $(220-800 \mathrm{~nm})$ against pure $\mathrm{KBr}$ disc as the reference. The $\mathrm{KBr}$ disc was prepared by mixing $1 \mathrm{mg}$ of each sample with $100 \mathrm{mg}$ of $\mathrm{KBr}$. Thickness of the disc was maintained $0.1 \mathrm{~mm}$ for each of the sample. The XRD patterns were recorded on a Rigaku (Geigerflex RB RU 200) X-ray diffractometer using $\mathrm{Cu} \mathrm{K}$ alpha radiation filtered by a nickel foil over the range of diffraction angle $3-50^{\circ}$, the wavelength used being $1.542 \mathrm{~A}^{\mathrm{o}}$. Thermograms of the sample are recorded on Perkin Elmer TG analyser up to $1000^{\circ} \mathrm{C}$ at a heating rate $10^{\circ} \mathrm{C}$ per minute in air atmosphere. SEM photographs of the samples were recorded on machine JEOL JSM - 6360A Analytical SEM.

\subsection{EDX-Analysis}

\section{Results and Discussion}

The EDX analysis is mainly used to identify the constituent elements and for knowing the relative percentages of these elements. These results are expressed in terms of bar diagram shown in the Fig-1.

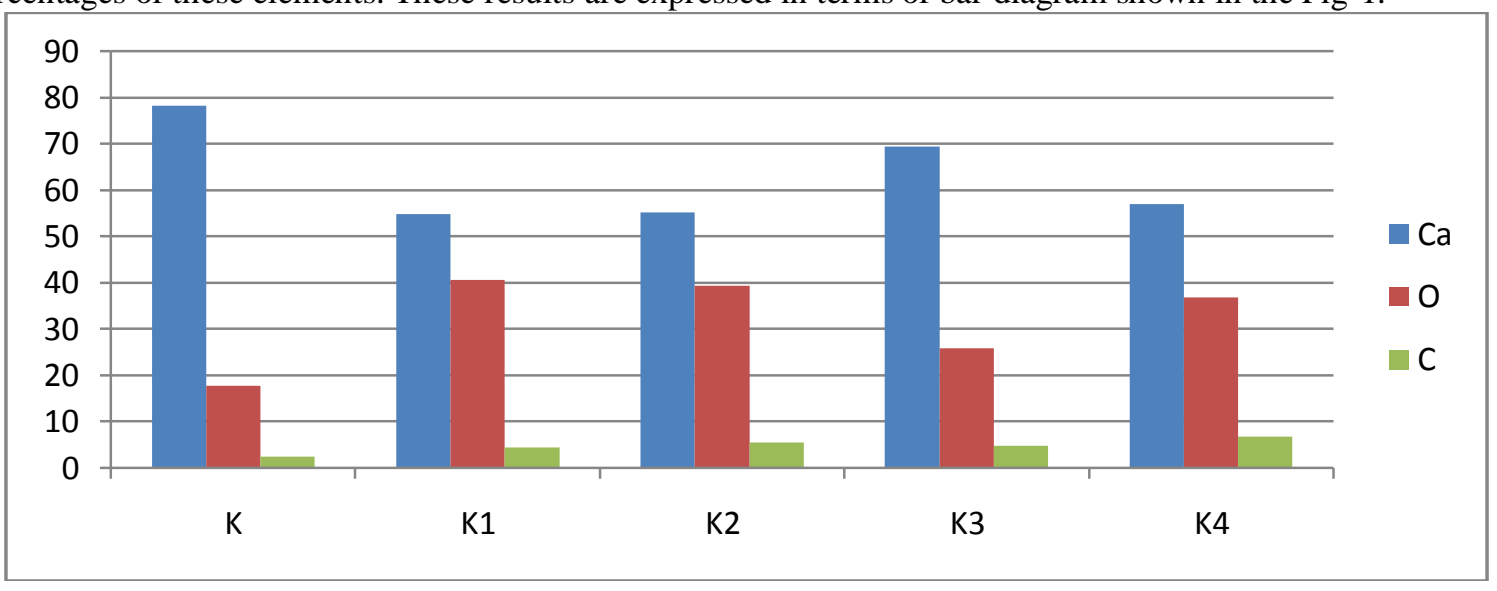

Fig-1 Bar Diagram showing relative percentage of constituent elements of Kapardika bhasmas

Pure and stoichiomertically correct $\mathrm{CaCO}_{3}$ is composed of $\sim 40 \% \mathrm{Ca}$ and $\sim 60 \% \mathrm{CO}_{3}$ but the commercial sample of $\mathrm{CaCO}_{3}$ of AR grade under study is associated with $\mathrm{MgO}(0.4 \%)$ as the impurity. Naturally occurring Kapardika powder also contains predominantly calcium, carbon and oxygen. But it is associated with sodium as a minor constituent. The four samples of Kapardika bhasma are also more predominantly composed of the mixture of calcium, carbon and oxygen. This important observation is further supported by IR studies.

\subsection{Infrared Spectroscopy}

Infrared spectra of Kapardika powder and samples of Kapardika bhasma are compared with standard $\mathrm{CaCO}_{3}$ because all these samples are mainly composed of $\mathrm{CaCO}_{3}$ as observed from EDX. IR spectra of all the samples are presented in Fig-2 and important frequencies are summarized in Table-2.

Conclusions from IR Study:

1. The IR spectrum of Kapardika powder shows characteristic peaks in the region $600-750 \mathrm{~cm}^{-1} \mathrm{confirming}^{-}$ presence of calcium carbonate ${ }^{[9]}$. Most of the samples of Kapardika bhasma also show two peaks in the same region.

2. In Synthetic $\mathrm{CaCO}_{3}$ and in K-1, K-2, K-4 broad bands in region around $3445-3642 \mathrm{~cm}^{-1}$ are observed. They are either due to $\mathrm{O}-\mathrm{H}$ from $\mathrm{H}_{2} \mathrm{O}$ present in the lattice ${ }^{[10]}$ or from $\mathrm{Ca}(\mathrm{OH})_{2}$ associated with $\mathrm{CaCO}_{3}{ }^{[11]}$ of respective samples except that of K-3 sample. 


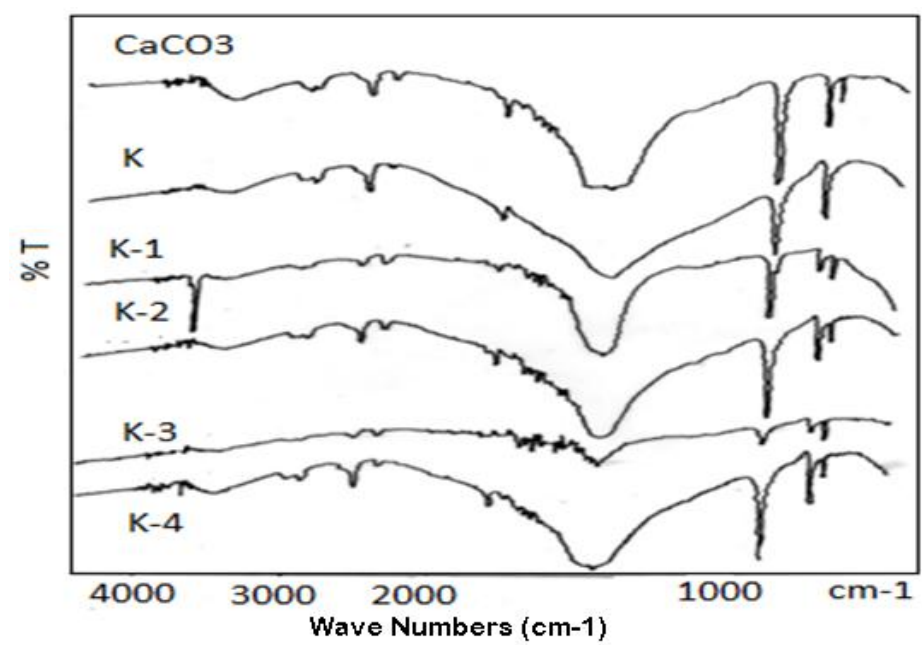

Fig -2 Infrared spectra of Kapardika powder and bhasmas.

Table-2 Infrared Frequencies of Kapardika Powder and Kapardika Bhasmas

\begin{tabular}{|c|c|c|c|c|c|c|c|c|c|c|}
\hline $\begin{array}{l}\text { Sr. } \\
\text { No }\end{array}$ & Compound & Peak-1 & Peak-2 & Peak-3 & Peak4 & Peak-5 & $\begin{array}{c}\text { Peak- } \\
6\end{array}$ & $\begin{array}{c}\text { Peak- } \\
7\end{array}$ & $\begin{array}{c}\text { Peak- } \\
8\end{array}$ & $\begin{array}{c}\text { Peak- } \\
9\end{array}$ \\
\hline & $\begin{array}{l}\text { Assignmen } \\
\text { t }\end{array}$ & $\begin{array}{l}\mathrm{O}-\mathrm{H} \\
\left(\mathrm{H}_{2} \mathrm{O}\right) / \\
\mathrm{Ca}(\mathrm{OH})_{2}\end{array}$ & $\begin{array}{l}\text { Organi } \\
\text { c mater }\end{array}$ & $\begin{array}{l}\text { Organic } \\
\text { mater }\end{array}$ & & $\mathrm{H}-\mathrm{O}-\mathrm{H}$ & $\mathrm{CO}_{3}{ }^{2-}$ & $\mathrm{CO}_{3}{ }^{2-}$ & $\mathrm{CO}_{3}{ }^{2-}$ & \\
\hline 1. & $\mathrm{CaCO}_{3}$ & 3445 & $\begin{array}{l}2887 \\
2872\end{array}$ & 2512 & 2360 & 1795 & $\begin{array}{l}1403 \\
1422\end{array}$ & 872 & 712 & 668 \\
\hline 2 & $\mathrm{~K}$ & 3446 & 2872 & 2512 & 2370 & 1799 & 1418 & 875 & $\begin{array}{l}740 \\
750\end{array}$ & $\begin{array}{l}--- \\
\end{array}$ \\
\hline 3 & K-1 & 3642 & ---- & 2512 & 2360 & 1809 & 1435 & 910 & $\begin{array}{l}712 \\
750\end{array}$ & ---- \\
\hline 4 & $\mathrm{~K}-2$ & 3447 & 2875 & 2512 & 2344 & 1799 & 1436 & 875 & $\begin{array}{l}712 \\
750\end{array}$ & $\begin{array}{l}600 \\
620\end{array}$ \\
\hline 5 & $\mathrm{~K}-3$ & ---- & $\begin{array}{l}--- \\
\end{array}$ & 2513 & 2330 & 1843 & 1436 & 874 & 712 & 668 \\
\hline 6 & $\mathrm{~K}-4$ & $\begin{array}{l}3444 \\
3673\end{array}$ & 2898 & 2509 & 2362 & 1791 & 1446 & 874 & $\begin{array}{l}726 \\
750\end{array}$ & ---- \\
\hline
\end{tabular}

3. In case of the Kapardika powder the broad peak around $3446 \mathrm{~cm}^{-1}$ is assignable to lattice water and associated organic matter ${ }^{[12]}$ which is further supported by thermal studies. In K-3 sample there is no indication of water molecule in its structure. In the spectrum of K-1 the peak around $3642 \mathrm{~cm}^{-1}$ is sharp which is rather surprising. The bands around $1795-1809 \mathrm{~cm}^{-1}$ could be assignable to $\mathrm{H}-\mathrm{O}-\mathrm{H}$ of water molecule from $\mathrm{CaCO}_{3}{ }^{[9]}$.

4. The broad peaks around $1422 \mathrm{~cm}^{-1}$ as well as sharp peaks around 872 and $772 \mathrm{~cm}^{-1}$ are due to carbonate ions $\left(\mathrm{CO}_{3}{ }^{-2}\right)$ from $\mathrm{CaCO}_{3}{ }^{[9]}$ in all five samples. The possible reasons for the presence of such peaks could be as follows. The preparation of Kapardika bhasma involves repeated treatment of Kapardika powder with medicinally important plants like Aloe Vera and repeated calcinations cycles in traditional furnace in an earthen pots where temperature in the furnace is between $600-900^{\circ} \mathrm{C}^{[13,14]}$. It is expected that the high temperature inside the furnace should result the conversion of $\mathrm{CaCO}_{3}$ present in the Kapardika powder into $\mathrm{CaO}{ }^{[15]}$ involving the reaction- (1) as follows.

$\mathrm{CaCO}_{3} \rightarrow \mathrm{CaO}+\mathrm{CO}_{2}$ (1)

But the Kapardika bhasma mainly shows the presence of $\mathrm{CaCO}_{3}$ in the form of calcite along with $\mathrm{Ca}(\mathrm{OH})_{2}$ in some bhasma samples. This observation is consistent with the observations reported by Ketakar etal and Dubey etal who have done rigorous investigation of Mukta Shouktik bhasma ${ }^{[13,14]}$ which is also a calcium carbonate based Ayurvedic bhasma. The repeated treatment of Aloe vera gel containing enough amount of water may prevent the decarboation of intermediate product of Kapardika bhasma ${ }^{\text {[16]. Possibility of }}$ decarbonation of Kapardika powder in the form of aragonite and reformation of calcium carbonate in form of calcite via calcium hydroxide is also reported by Mishra etal and Krishna etal. ${ }^{[5]}$ Calcium oxide formed due to calcinations in Reaction (1) has a great affinity for water to give $\mathrm{Ca}(\mathrm{OH})_{2}$ through the reaction (2)

$\mathrm{CaO}+\mathrm{H}_{2} \mathrm{O} \rightarrow \mathrm{Ca}(\mathrm{OH})_{2}$

$\mathrm{Ca}(\mathrm{OH})_{2}+\mathrm{CO}_{2} \rightarrow \mathrm{CaCO}_{3}$

This $\mathrm{Ca}(\mathrm{OH})_{2}$ again reacts with $\mathrm{CO}_{2}$ present in the sealed earthen pot to give again $\mathrm{CaCO}_{3}$ by reaction(3). The reactions (1), (2) and (3) take place simultaneously. But since the reaction is taking place in closed 
system reaction (3) could be dominant due to presence of accumulated $\mathrm{CO}_{2}$ in the earthen pot. This observation is also consistent with the detailed studies done by wadekar etal ${ }^{[2]}$ on effect of calcinations cycles on preparation of vanga bhasma where the bhasma contains $\mathrm{CaCO}_{3}$ along with tin oxide.

5. The peaks around $2870-2890 \mathrm{~cm}^{-1}$ are assignable to the asymmetric and symmetric stretching vibrations of $\mathrm{sp}^{3}$ hybridized $\mathrm{C}-\mathrm{H}$ bands and the peaks around $2509-2513 \mathrm{~cm}^{-1}$ are attributed to organic matters which contained hydroxyl matter. ${ }^{[10]}$

\subsection{Electronic Spectroscopy}

Solid state UV-Visible spectra of Kapardika powder and samples of Kapardika bhasmas are compared with standard $\mathrm{CaCO}_{3}$ and Spectra of all the samples are presented in Fig-3 and important wavelengths along with their tentative assignments are shown in Table-3

Table-3 Solid State Electronic Spectra ( $\lambda$ max in nm) of Kapardika powder and Kapardika bhasmas.

\begin{tabular}{|c|c|c|c|c|c|}
\hline Compound & Peak-1 & Peak-2 & Peak-3 & Peak-4 & Peak-5 \\
\hline Assignments & $\boldsymbol{\sigma}-\boldsymbol{\pi}^{*}$ & $\boldsymbol{\sigma}-\boldsymbol{\pi}^{*}$ & $\boldsymbol{\pi}-\boldsymbol{\pi}^{*}$ & $\boldsymbol{\pi}-\boldsymbol{\pi}^{*}$ & $\mathbf{n}-\boldsymbol{\pi}^{*}$ \\
\hline $\mathrm{CaCO} 3$ & --- & 239 & 270 & 302,344 & --- \\
\hline $\mathrm{K}$ & --- & --- & 266 & 340 & 402 \\
\hline $\mathrm{K}-1$ & 222 & 239 & 270 & 344 & 418 \\
\hline $\mathrm{K}-2$ & 222 & 239 & 270 & 344 & 399 \\
\hline $\mathrm{K}-3$ & --- & 239 & 270 & 344 & 538 \\
\hline $\mathrm{K}-4$ & 224 & 239 & 270 & 344 & 407 \\
\hline
\end{tabular}

\subsection{X- ray powder Diffraction}

The XRD patterns of $\mathrm{CaCO}_{3}$, Kapardika powder and four samples of Kapardika bhasma, are illustrated in Fig- 4. These XRD patterns show that all the samples include $\mathrm{CaCO}_{3}$ as their major component. These patterns are composed of sharp lines with different intensities. From the nature of these lines it reveals that all these samples are crystalline in nature. The diffraction peak at $\left(2\right.$ theta $\left.=30.34^{0} \mathrm{~A}\right)$ Kapardika powder and the diffraction peaks $\left(2\right.$ theta $\left.=29.78-28.99^{\circ} \mathrm{A}\right)$ in all samples of bhasma indicate possibility of calcite phase of calcium carbonate ${ }^{[10,14]}$. The Particle size calculated from these XRD patterns using Scherrer Equation are shown in Table- 4 which falls in the range $28 \mathrm{~nm}$ to $40 \mathrm{~nm}$ indicating their nanometric nature. This size is lower than the standard $\mathrm{CaCO}_{3}$.

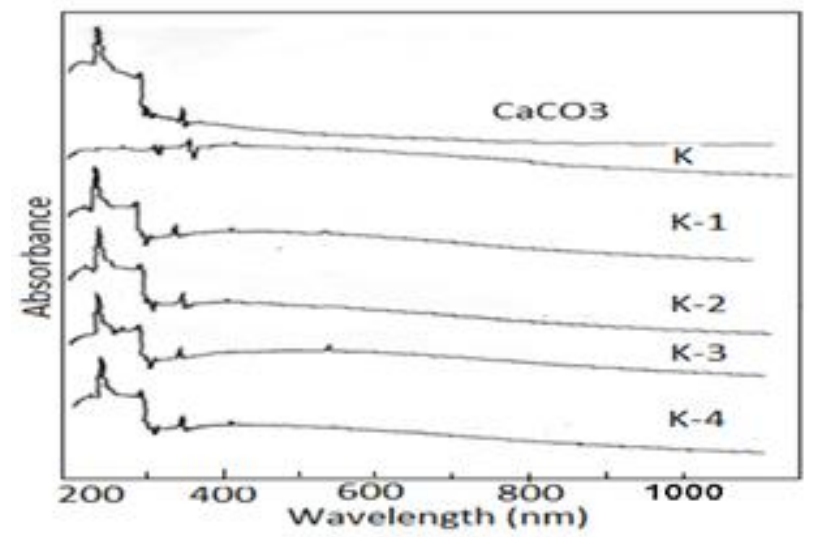

Fig -3 Electronic spectra of Kapardika powder and Kapardika bhasma. 


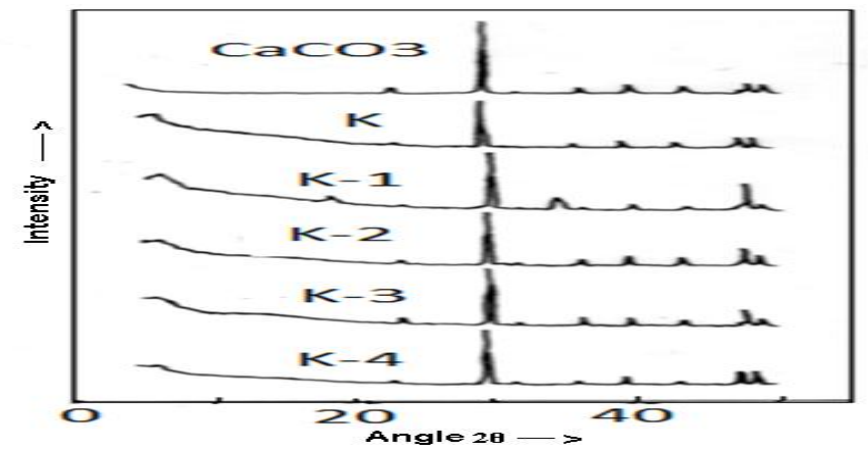

Fig-4 XRD patterns of Kapardika powder and Kapardika bhasmas.

Table- 4 Particle Size of Kapardika and Kapardika bhasmas

\begin{tabular}{|l|l|l|l|l|}
\hline Sr. No & $\begin{array}{l}\text { Name of the } \\
\text { Compound }\end{array}$ & FWHM & Angel 20 & $\begin{array}{l}\text { Particle Size } \\
(\mathbf{n m})\end{array}$ \\
\hline 1 & $\mathrm{CaCO}_{3}$ & 0.1897 & 29.5421 & 43.32 \\
\hline 2 & $\mathrm{~K}$ & 0.2544 & 30.3427 & 32.36 \\
\hline 3 & $\mathrm{~K}-1$ & 0.2096 & 29.7876 & 39.23 \\
\hline 4 & $\mathrm{~K}-2$ & 0.2929 & 29.5594 & 28.06 \\
\hline 5 & $\mathrm{~K}-3$ & 0.2307 & 29.7450 & 35.64 \\
\hline 6 & $\mathrm{~K}-4$ & 0.2582 & 28.9998 & 31.79 \\
\hline
\end{tabular}

\subsection{Thermo-gravimetric Analysis}

Thermo-gravimetric analysis patterns of Kapardika powder and respective bhasmas are presented in Fig-5 and the important conclusions are summarized in Table-5 which supports $\mathrm{CaCO}_{3}$ as major component in them along with small amount of organic matter and water or calcium hydroxide. Weight losses for $\mathrm{CO}_{2}$ and weight of residues remaining at the end as $\mathrm{CaO}$ are matching well with the calculated weights. These results indicate that Kapardika powder contains $83 \% \mathrm{CaCO}_{3}$ and the bhasma samples contain $98-99 \% \mathrm{CaCO}_{3}$.

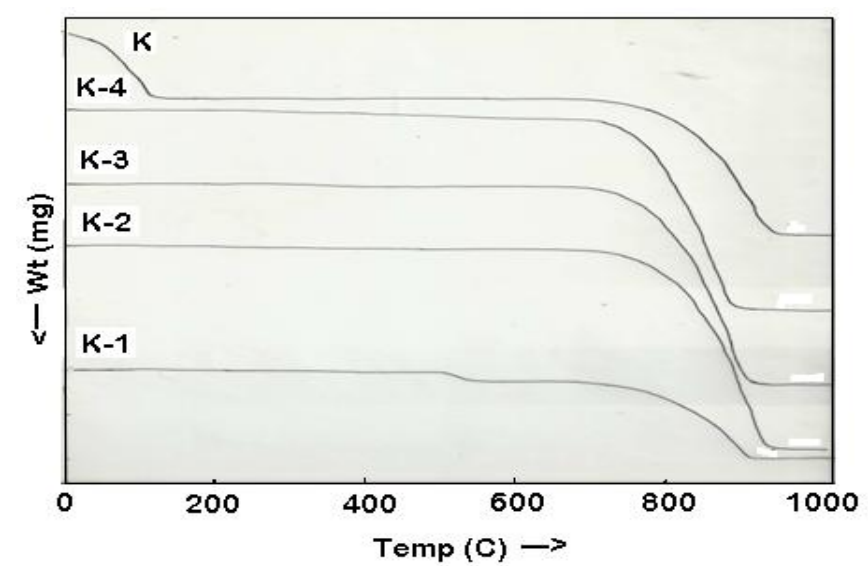

Fig-5 Thermo-gravimetric patterns of Kapardika powder and Kapardika bhasmas

\subsection{SEM Studies}

The SEM photographs of pure $\mathrm{CaCO}_{3}$, Kapardika powder and samples of Kapardika bhasma at three magnifications are shown in Fig-6. A comparison of the SEM photographs of Kapardika powder with the SEM photographs of Kapardika bhasma shows that samples of Kapardika bhasma exhibits remarkable difference in their morphology. They seems to be composed of lumps or agglomeration which are heterogeneous in nature consisting of different sizes of crystallites. The conclusions from SEM studies may be summarized as follows: (i) The Kapardika powder is a mixture of square shaped and rod shaped particles and the particle size ranges in between 0.5 to 1 micron. The reason of such mix particles could be, naturally occurring Kapardika is the hardest material among all the marine products and it is more difficult to transform it into finely divided powder form . 
Due to this reason, special methods for the ayurvedic purification of Kapardika itself and its crude powder are recommended to transform it into finely divided powder form.

Table-5 Thermal decomposition Steps of Kapardika powder and Kapardika bhasmas.

\begin{tabular}{|c|c|c|c|c|}
\hline $\begin{array}{l}\text { Compound } \\
\text { with initial } \\
\text { wt }\end{array}$ & $\begin{array}{l}\text { Decomposition } \\
\text { Steps }\end{array}$ & $\begin{array}{l}\text { Temperature } \\
\text { range }{ }^{0} \mathrm{C}\end{array}$ & $\begin{array}{l}\text { Wt loss } \\
(\mathrm{mg})\end{array}$ & Assignments \\
\hline \multirow{3}{*}{$\begin{array}{l}\mathrm{K} \\
43 \mathrm{mg}\end{array}$} & $\mathrm{I}$ & $50-140$ & 7.00 & Loss due to organic matter and lattice water. \\
\hline & II & $700-925$ & $\begin{array}{l}15.10 \\
(15.84)\end{array}$ & Loss due to $\mathrm{CO}_{2}$ from $\mathrm{CaCO}_{3}$ \\
\hline & & & & Residue as $\mathrm{CaO}=21.00(20.16) \mathrm{mg}$ \\
\hline \multirow{4}{*}{$\begin{array}{l}\mathrm{K}-1 \\
10 \mathrm{mg}\end{array}$} & I & $50-460$ & 0.10 & Loss due to organic matter \\
\hline & II & $460-501$ & 0.40 & Loss due to organic matter \\
\hline & III & $650-850$ & $\begin{array}{c}3.50 \\
(4.18) \\
\end{array}$ & $\begin{array}{l}\text { Loss due to } \mathrm{CO}_{2} \text { from } \mathrm{CaCO}_{3} \text { and from small } \\
\text { amount of } \mathrm{Ca}(\mathrm{OH})_{2}\end{array}$ \\
\hline & & & & Residue as $\mathrm{CaO}=6.00(5.32) \mathrm{mg}$ \\
\hline \multirow{3}{*}{$\begin{array}{l}\mathrm{K}-2 \\
40 \mathrm{mg}\end{array}$} & $\mathrm{I}$ & $50-375$ & 0.30 & Loss due to organic matter \\
\hline & II & $800-925$ & $\begin{array}{c}17.20 \\
(17.60) \\
\end{array}$ & Loss due to $\mathrm{CO}_{2}$ from $\mathrm{CaCO}_{3}$ \\
\hline & & & & Residue as $\mathrm{CaO}=22.5$ (22.4) $\mathrm{mg}$ \\
\hline \multirow{3}{*}{$\begin{array}{l}\mathrm{K}-3 \\
19.50 \mathrm{mg}\end{array}$} & $\mathrm{I}$ & $50-375$ & 0.1 & Loss due to organic matter \\
\hline & II & $720-900$ & $\begin{array}{l}8.60 \\
(8.53) \\
\end{array}$ & Loss due to $\mathrm{CO}_{2}$ from $\mathrm{CaCO}_{3}$ \\
\hline & & & & Residue as $\mathrm{CaO}=12.80(12.86) \mathrm{mg}$ \\
\hline \multirow{3}{*}{$\begin{array}{l}\mathrm{K}-4 \\
13.00 \mathrm{mg}\end{array}$} & $\mathrm{I}$ & $50-540$ & 0.4 & Loss due to organic matter \\
\hline & II & $725-875$ & $\begin{array}{l}5.60 \\
(5.72) \\
\end{array}$ & Loss due to $\mathrm{CO}_{2}$ from $\mathrm{CaCO}_{3}$ \\
\hline & & & & Residue as $\mathrm{CaO}=7.00(7.20) \mathrm{mg}$ \\
\hline
\end{tabular}

The values in the parentheses indicate calculated values.

(ii) The K-1 sample of bhasma shows high degree of agglomeration and the particle size ranges between 0.5 to 0.7 micron. These agglomerates appear to be square shaped and porous.

(iii) K-2 sample is composed of porous agglomerates and particle size is ranging from 0.7 to 0.1 micron. The shape of the particles is circular granules.

(iv) In K-3 also agglomeration is observed and the big particles are covered by small dusty particles as that of for $\mathrm{K}-2$.The particle size ranges from 0.5 to 1 micron.

(v) The K-4 sample shows particles of 0.5 to 0.7 micron with loss of their grain boundaries. Higher degree of agglomeration is a consequence of repeated calcinations cycles during the preparation of these bhasmas ${ }^{[2]}$.

\section{Conclusions}

A comparative study of Kapardika powder and four commercial samples of Kapardika bhasma are carried out using modern instrumental techniques. These samples are mainly composed of calcium carbonate as indicated by EDX, IR and TGA. TGA is found to be the most useful technique for compositional studies of these bhasmas. Four samples of Kapardika bhasma resembles with each other with minor differences due to presence of small quantity of water, calcium hydroxide and organic matter. XRD of the four samples match with calcite phase of calcium carbonate and indicate nanometric nature of the bhasmas. Such nanometric Size could be responsible for the excellent therapeutic properties of the bhasmas.Further presence of organic matter as shown by IR and TG is likely to influence the bioassemibility of the bhasma. SEM analysis reveals agglomeration of the particles as consequences of repeated calcination cycles subjected during preparation of these bhasmas. Morphology of these samples is remarkably different from each other as seen from SEM photographs.
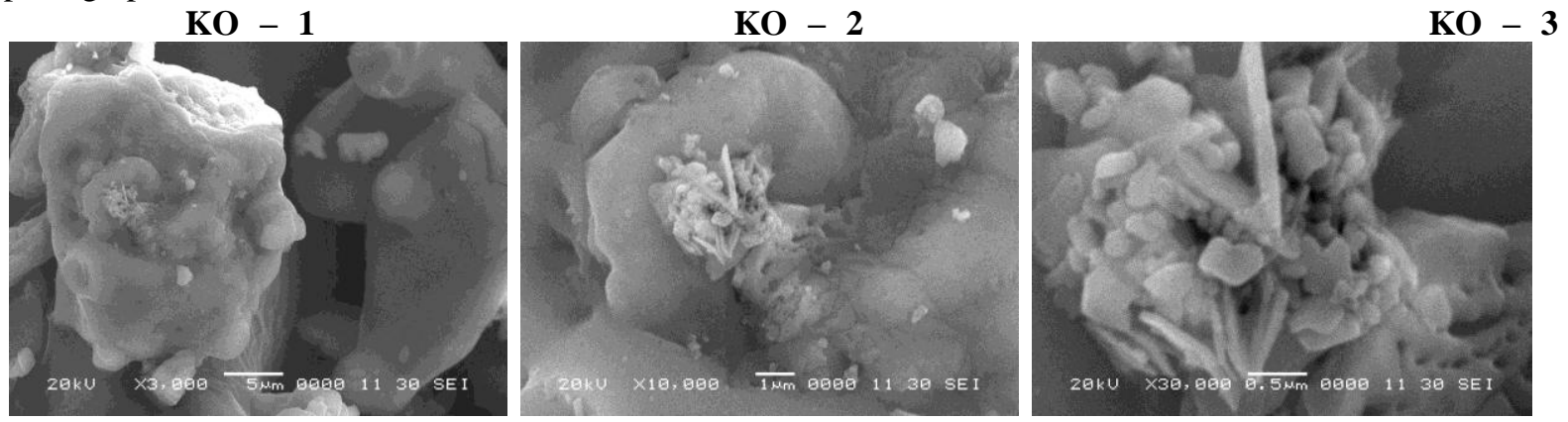
K1 - 1

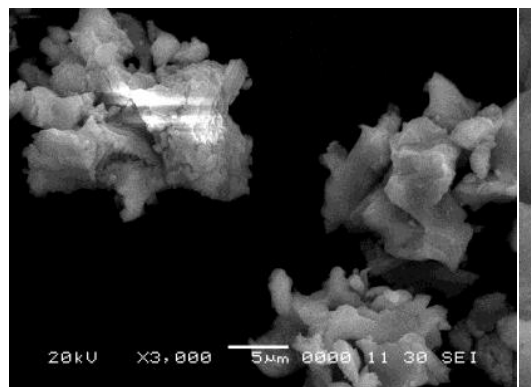

K2 - 1

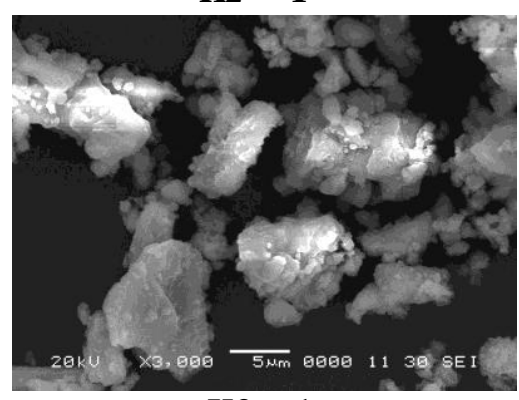

K3 - 1

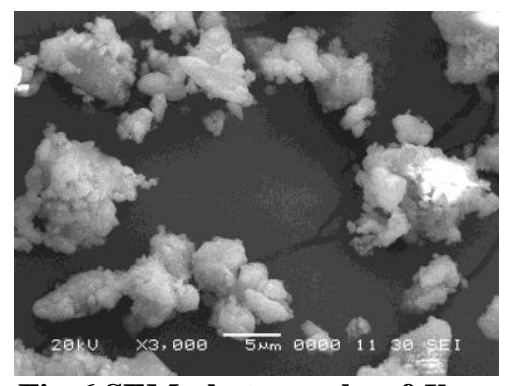

K1 - 2

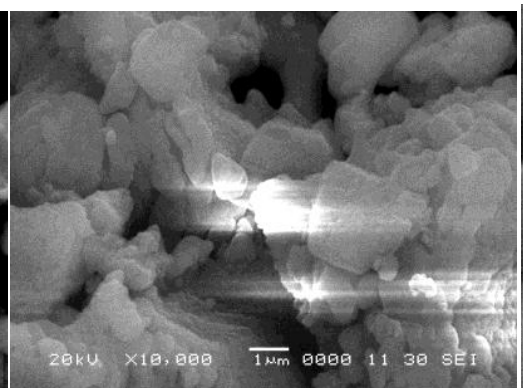

K2 - 2

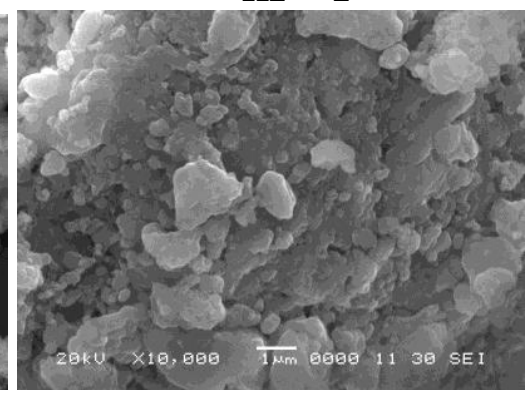

K3 - 2

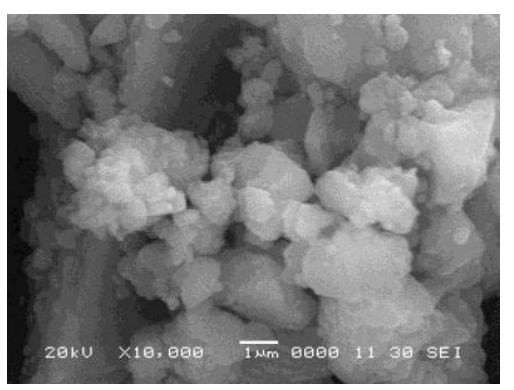

K1 - 3

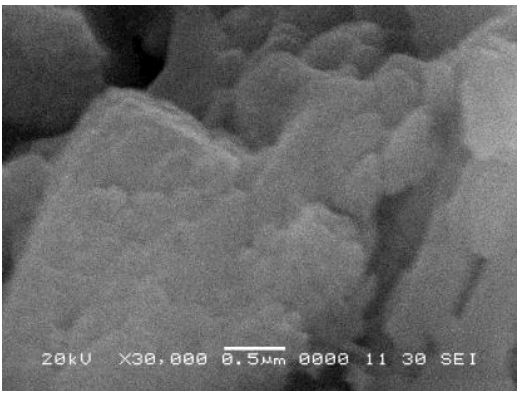

K2 - 3

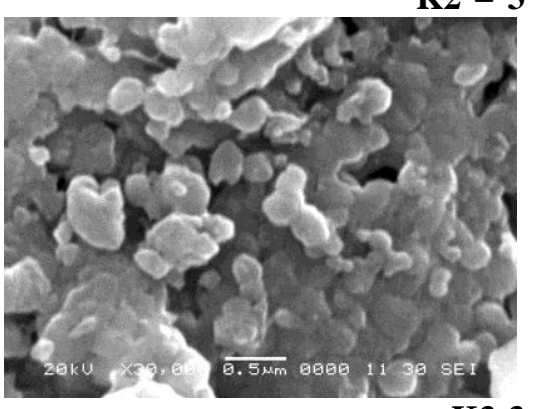

K3-3

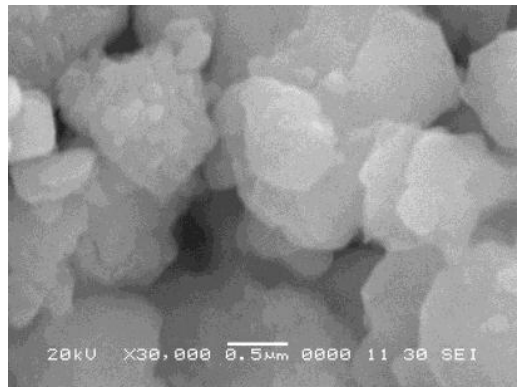

Fig-6 SEM photographs of Kapardika powder and Kapardika bhasmas K-1,K-2, K-3.
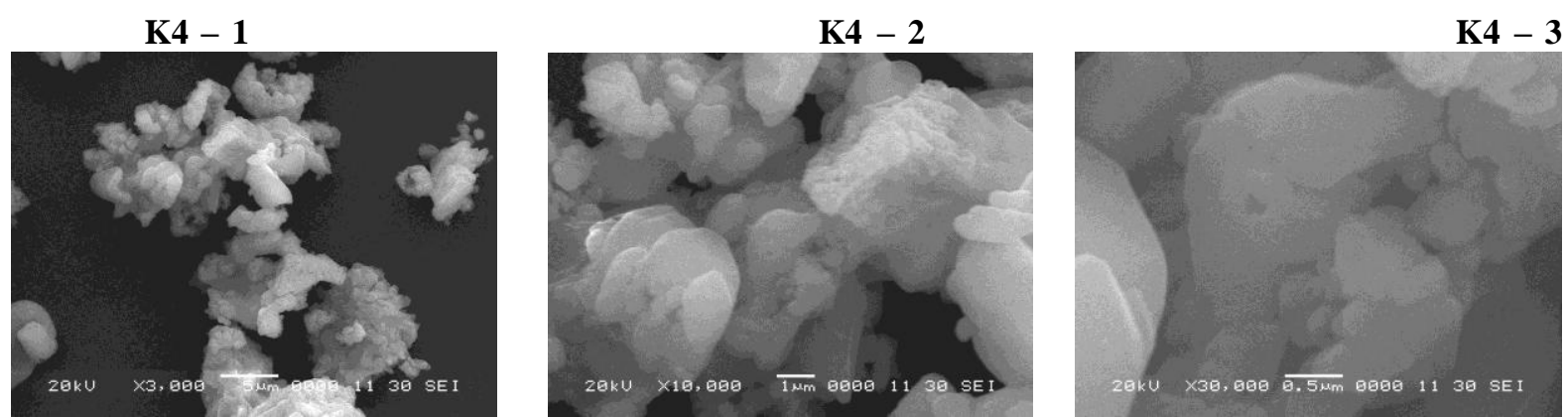

Fig-6 SEM photographs of Kapardika bhasma sample $K-4$

These findings may help the preparation of standard and reproducible formulation of kapardika bhasma.

\section{Acknowledgements}

Authors are thankful to Dr. S.S. Kadam, Vice Chancellor, Bharati Vidyapeeth Deemed University, Pune, Prof. K.D. Jadhav, Principal, Y.M. College, Pune, for providing necessary facilities and constant encouragement. Authors are also thankful to Dr. P.S. Khandagale and Dr. P.K. Khanna for their valuable suggestions.

\section{References}

[1] Wadekar M.P., Rode C.V., Bendale Y.N, Patil K.R., Prabhune A.A., Preparation and characterization of a copper based Indian traditional drug: Tamra bhasma. Journal of pharmaceutical and biomedical analysis, 39,2005,951-955.

[2] Wadekar M.P., Rode C.V., Bendale Y.N., Patil K.R., Gaikwad, Prabhune A.A., Effect of calcinations cycles on the preparation of tin oxide based traditional drug: Studies on its formation and characterization., Journal of pharmaceutical and biomedical analysis.,41,2006,1473-1478.

[3] Mrudula Wadekar, Vishwas Gogte, Prasad Khandagale and Asmita Prabhune. Comparative study of some commercial samples of Naga Bhasma., Ancient Science of Life, 23(4),2004, 45-48. 
[4] Mrudula Kulkarni, G.T. Panse, B.A. Kulkarni and Yogesh Bendale. Characterization of Raupya Bhasma by using modern analytical techniques., Journal of Indian Medicine and Homeopathy, January-March, 2004,37-43.

[5] Kulshrestha Mayanka Krishna, Karbal Kamleshwar Singh., A critical review on Ayurvedic drug Kapardika (Cypraea Moneta Linn), International research Journal of Pharmacy, 3(10), 2012.

[6] Devanathan R., Rajalakshmi P. P. and Brindha P., Chemical Standardisation studies on Varatika Bhasma, International Journal of Pharmaceutical research, 2(4), 2010, 12-16.

[7] Kumar A., Nair A. G.C., Reddy A. V. R. and Garg A. N., Availability of essential elements in bhasmas: Analysis of Ayurvedic metallic preparations by INAA, Journal of Radio-analytical and Nuclear Chemistry, (270)1, 2006, 173-180.

[8] A. J. Baxi and S. A. Vasavada, Antacid activity of some Ayurvedic calcium preparations, Indian J. Pharmacy, 27, 1965,227-230.

[9] Flemming A. Andersen and Ljerka Brecevic, Infrared spectra of amorphous and crystalline calcium carbonate, Acta Chemica Scandinavica ,45,1991, 1018-1024.

[10] Wenlong Wu, Liping Zhang, Zhijun Yang and Weisheng Hou., Study on microstructure of the Pinctada martensii pearls and its significance., International Scholarly Research Network ISRN spectroscopy, article ID 756217, $2012,9$.

[11] FTIR and XRD analysis of mineral and organic matrix during heating of mother pearl from shell of the mollusc pinctada maxima., Balmain J., Hannoyer B and Lopez E, Journal of Biomedical material Research, 48(5), 1999,749-754.

[12] Meena Devi, P. Nagendra Prasad and K. Kalirajan., Infrared spectral studies on siddha drug-Pavalaparpam., International journal of pharma and biosciences, 1(4), 2010, 474-483.

[13] Ketkar A R, Kadam H.M. and Paradkar A.R., Temperature variability during preparation of shouktic bhasma and its consequences, Indian Drugs. 40(6),2003, 363-365.

[14] Nitin Dubey, Nidhi Dubey, Rajenndra S. Mehta, Ajay K. Saluja and Dinesh Jain., Physiological and pharmacological assessment of a traditional biomedicine: Mukta shouktic bhasma., Songklanakarin J. Sci, Technol,31(5), 2009,501-510.

[15] Engin, B. Demirtas H., Eken M., Temperature effects on egg shells investigated by XRD, IR and ESR techniques., Radiation physics and chemistry.,75,2006, 268-277.

[16] Ketkar A R, Borde P. P., Kadam H.M. and Paradkar A.R., Role of Aloe vera juice treatment(bhavana) in preparation of shouktic bhasma., Indian Drugs.,39(12), 2002, 661-663. 